\title{
Effect of Contrast Media used in Coronary Angiography on Thyroid Function
}

\author{
Khaled S. El-Hadidy ${ }^{1}$, Rania E. Sheir', M.N. Salem¹, Ahmed M. EL-Dien ${ }^{1}$, Yasser A. Abd El-Hady ${ }^{2}$ \\ ${ }^{1}$ InternalMedicine Department, Faculty of Medicine, Beni-Suef University, Egypt \\ ${ }^{2}$ Cardiology Department, Faculty of Medicine, Beni-Suef University, Egypt
}

\begin{abstract}
Radiocontrast-induced thyroid dysfunction prevalence has not been assessed accurately. It is greater among patients with pre-existing thyroid disease. Aim of this work to investigate effect of iodinated radiographic contrast media used in coronary angiography on the thyroid function in euthyroid patients. This study was conducted on 85 patients underwent elective coronary angiography. Baseline assessment of Free Thyroxine (FT4) and Thyroid-stimulating hormone (TSH) for the patients and three months later after Coronary Angiography. We observed that there was a statistically significant increase of TSH levels from baseline till 3 months following administration of contrast media ( $\mathrm{P}$-value $=0.007)$. However, there was no statistical significant difference of Free T4 level from baseline till 3 (P-value=0.765). The incidence of increased TSH above normal range was $2.4 \%$ after 3 months ( 2 subclinical hypothyroidism cases). We noticed that there were no effect of age, gender, hypertension, diabetes, type of contrast, creatinine level or GFR on increased the level of TSH above normal value after 3 months. So, administration of Iodinated Contrast Media (ICM) associated with thyroid dysfunction mainly subclinical hypothyroidism so we should closely monitor patients after receiving ICM especially who have thyroid dysfunction.
\end{abstract}

Keywords : Coronary Angiography, Iodinated Contrast Media, Thyroid function, Wolff-Chaikoff effect.

\section{INTRODUCTION}

As we know the thyroid hormones play important rule in regulation of metabolism, heat production , reproduction, and many other body functions, so thyroid dysfunctions lead to multiple abnormal [1].Iodine is an essential element in thyroid hormones synthesis hence both iodine deficiency and excess intake may lead to thyroid dysfunction [2].The recommended daily iodine intake for non pregnant nor lactating adults is $150 \mu \mathrm{g}[3]$.Contrast medias contain iodine which provides excellent radio-opacity ,A dose of contrast media used in coronary angiography (Diagnostic or Theraputic) is an acute iodide load of 90 to several hundred thousand times the recommended daily intake of iodide [4]. The normal response to a high iodine load is the acute Wolff-Chaikoff effect intially then escape from this effect. Failure of this effect results in iodine-induced hyperthyroidism or the JodBasedow phenomenon but in case of failure to escape from the effect results in iodine-induced hypothyroidism [5] .The hyperthyroidism may be due to hyperfunctioning quiescent nodules after exposure to excess iodine. Risk factors include simple goiter, latent Graves' disease, and longstanding iodine deficiency but in case of hypothyroidism occurs mainly in patients with prior 
history of thyroditis or previously treated euthyroid patients of graves' disease [6].

In our study we investigate the long-term effect of ICM used in coronary angiography on thyroid functions of euthyroid patients.

\section{METHODS AND MATERIAL}

This study was prospective follow up study conducted on eighty five Egyptian patients from Beni-Suef Government admitted in cardiology department of Beni-Suef Univeristy Hospital. We studied the effect of iodinated contrast material used in patients candidate for elective coronary angiography on thyroid functions.

Inclusion criteria: Adult euthyroid patients undergoing elective coronary angiography in cardiology department of Beni-Suef University Hospital.

Exclusion criteria : 1)Patients with history of Thyroid disease or palpable goiter by examination. . 2)Family history of Thyroid diseases. 3)Use of thyroid replacement, anti-thyroid drugs , Steroid, Immunosuppressive or Immunomodulatory drugs (e.g. Interferons) or iodine-containing medications in the past 6 months (e.g. Amiodarone).4)Recent (within the past 6 months) iodinated contrast investigations (e.g. angiography \& Radiography) and Radiation exposure.5) Renal failure ( GFR $<30$ $\mathrm{ml} / \mathrm{min} / 1.73 \mathrm{~m} 2$ ), Hepatic diseases (HCV infection and Liver cirrhosis), Cardiac decompansation and Autoimmune diseases.

All patients were subjected to the following:

*History taking: including; age, gender, geographical location, occupation, medical and family history.

* Clinical examination: Completed local thyroid gland examination.

${ }^{*}$ Laboratory investigations:
The following laboratory tests were done to the patients before the coronary intervention :

1- Baseline assessment of Free Thyroxine (FT4) ( Normal Range 0.8-1.8 ng/dl) and Thyroidstimulating hormone (TSH) (Normal Range 0.4-5 $\mu \mathrm{IU} / \mathrm{ml}$ ) by Enzyme-Linked Immunosorbent Assay (ELISA)( AccuBind® ELISA,USA).

2-Serum creatinine and calculation estimated Glomerular filtration rate (eGFR) using Modification of Diet in Renal Disease (MDRD) equation [7].

Three months later patients contacted to follow up their thyroid function testes (TSH\&FT4).

\section{III.RESULTS AND DISCUSSION}

The total number of patients were eighty five patients, there was 60 male patients $(70.6 \%)$ and 25 female patients (29.4\%) included, their age ranged from 33-84 years with mean of $(58.4 \pm 8.8)$ years. Eighty three $(44.7 \%)$ of patients were hypertensive and fifty five (64.7\%) were diabetic Table (1).

Table (1) Baseline laboratory characteristics of patients under the study

\begin{tabular}{|l|c|}
\hline Characteristics & Values \\
\hline Creatinine (mg/dl) & 0.99 \\
Mean & 0.19 \\
SD & 0.6 \\
Minimum & 1.5 \\
Maximum & 1 \\
Median & \\
\hline GFR (ml/min/1.73m2) & 75.3 \\
Mean & 21.04 \\
SD & 39.33 \\
Minimum & 139.88 \\
Maximum & 71.17 \\
Median & \\
\hline TSH $(\mu \mathrm{IU} / \mathrm{ml})$ & 1.57 \\
Mean & \\
\hline
\end{tabular}




\begin{tabular}{|l|c|}
\hline SD & 1.04 \\
Minimum & 0.4 \\
Maximum & 5 \\
Median & 1.3 \\
\hline Free T4(ng/dl) & \\
Mean & 1.34 \\
SD & 0.26 \\
Minimum & 0.8 \\
Maximum & 1.8 \\
Median & 1.3 \\
\hline
\end{tabular}

Iodinated Contrast Media Used in Coronary Angiography Table(2):

A-Non- Ionic dye (54 patients)

Used mainly in old or renal impaired patients

1- Ultravist 300mg $\backslash \mathrm{ml}$ (iopromide) (24 patient).

2- Omnipaque $300 \mathrm{mg} \backslash \mathrm{ml}$ (iohexol) (30 patient).

B-Ionic dye (31 patients)

Telebrix-35 350mg $\backslash \mathrm{ml}$ (ioxitalamic Acid).

Table (2) Characteristics of contrast of patients under the study

\begin{tabular}{|l|c|}
\hline Characteristics $\mathbf{( N = 8 5 )}$ & Values \\
\hline Type of contrast $\mathrm{NO}(\%)$ & $31(36.5)$ \\
Ionic & $54(63.5)$ \\
Non-ionic & \\
\hline Dose of contrast (ml) & 76.17 \\
Mean & 67.47 \\
SD & 25 \\
Minimum & 400 \\
Maximum & 50 \\
Median & \\
\hline
\end{tabular}

We observed that there was a statistically significant increase of TSH level from its baseline level to its level 3 months following exposure to contrast material (P-value=0.007) Table (3) \& Fig. (1).
Table (3) Follow up of TSH level from baseline till 3 months after the intervention

\begin{tabular}{|l|c|l|}
\hline Parameters & Baseline(N=85) & $\begin{array}{l}\text { After3 } \\
\text { months(N=85) }\end{array}$ \\
\hline Mean & 1.6 & 2.1 \\
SD & 1 & 1.9 \\
Median & 1.3 & 1.6 \\
\hline P-value & \multicolumn{2}{|c|}{$0.007^{*}$} \\
\hline
\end{tabular}

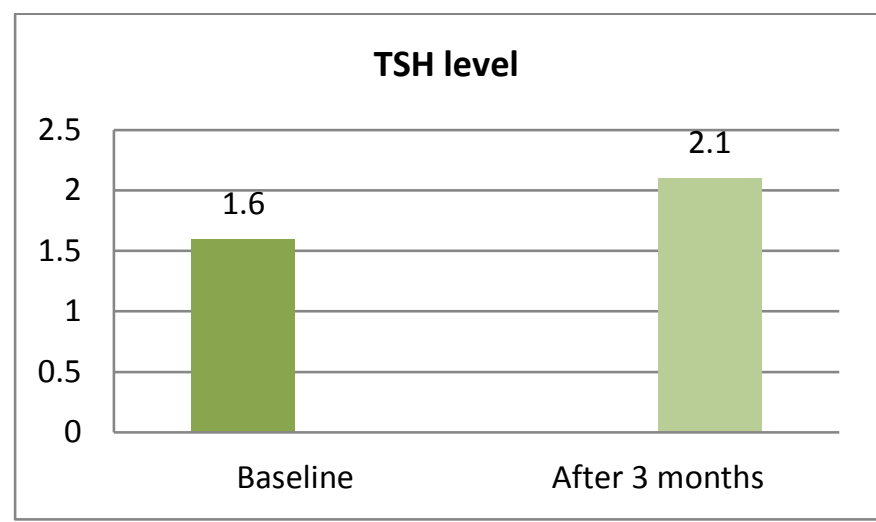

Figure 1. Follow up of TSH level from baseline till 3 months

However, there was no statistical significant difference of free T4 level from baseline till 3 months (P-value $=0.765)$ Table $4 \&$ Figure 2.

Table (4) Follow up of free T4 level from baseline till 3 months after the intervention

\begin{tabular}{|l|c|c|}
\hline Parameters & Baseline(85) & $\begin{array}{l}\text { After } \\
\text { months(85) }\end{array}$ \\
\hline Mean & 1.3 & 1.3 \\
SD & 0.3 & 0.4 \\
Median & 1.3 & 1.3 \\
\hline P-value & \multicolumn{2}{|c|}{0.765} \\
\hline
\end{tabular}




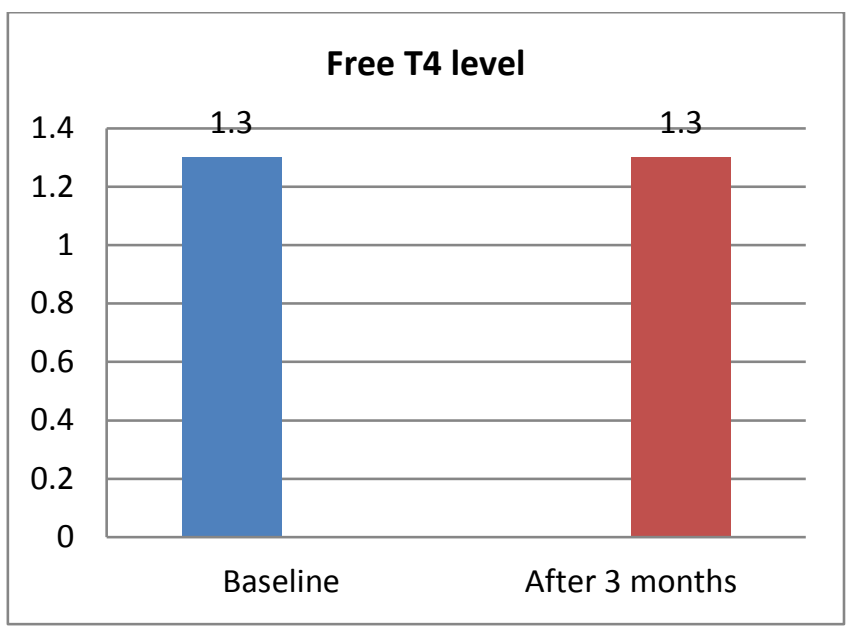

Fig.(2) : Follow up of free T4 level from baseline till 3 months

In our study,we found that there were no effect of age, gender, hypertension, diabetes, type of contrast, creatinine level or GFR on increased the level of TSH above normal value after 3 months Table (6).

Table (6) Binary logistic regression analysis of risk factors that may lead to increased TSH level after 3 months (multivariate analysis)

\begin{tabular}{|c|c|c|c|c|}
\hline \multirow{2}{*}{$\begin{array}{l}\text { Risk factors for Increased TSH after } \\
3 \text { months }(85)\end{array}$} & \multirow{2}{*}{$\begin{array}{r}\mathrm{P}- \\
\text { value }\end{array}$} & \multirow[t]{2}{*}{ OR } & \multicolumn{2}{|c|}{ 95\% Confidence Interval for OR } \\
\hline & & & Lower Bound & Upper Bound \\
\hline Intercept & 0.340 & & & \\
\hline Age (scale) & 0.495 & 1.04 & 0.927 & 1.16 \\
\hline Creatinine (scale) & 0.463 & 0.155 & 0.000 & 0.11 \\
\hline GFR $(<60)$ & 0.528 & 1.04 & 0.918 & 1.18 \\
\hline Gender(female) & 0.819 & 0.66 & 0.019 & 23 \\
\hline Presence Hypertension & 0.117 & 0.14 & 0.013 & 1.6 \\
\hline Presence of Diabetes & 0.282 & 3.2 & 0.381 & 27.5 \\
\hline Contrast (nonionic) & 0.735 & 0.74 & 0.125 & 4.3 \\
\hline
\end{tabular}

Our results showed that showed that there was a statistically significant increase of TSH level from its baseline level to its level 3 months following exposure to contrast material $(\mathrm{P}-\mathrm{value}=0.007)$ (Table 3 \&Figure 1) and no statistical significant difference of free $\mathrm{T} 4$ level (P- value=0.765) (Table 4\&Figure2). The incidence of increased TSH above normal range was $2.4 \%$ ( 2 cases of subclinical hypothyroidism) after 3 months. In a binary logistic regression analysis of risk factors that may lead to increased TSH level after 3 months (multivariate analysis) there were no effect of age, gender, hypertension, diabetes, type of contrast, creatinine level or GFR on increased the level of TSH above normal value after 3 months (Table 6).
In agreement with our results, Gartner and Weissel [8]studied the effect of contrast media on 22 euthyroid patients (coronary angiography: $n=16$; CT: $\mathrm{n}=6$ ), and they found significant increases in serum TSH level in $18 \%$ of patients within $3-5$ days $(p<0,01)$ with no change in Free T4 \& T3.

In Iranian study Moradirizi et al. [9] conducted on 70 euthyroid patients underwent coronary angiography revealed that 8 patients developed subclinical hypothyroidism $(\mathrm{p}=0.018)$ after one month.

On the other hand Koroscil et al. [10] stated that there was no significant changes in TSH,Total T4 or Total

T3. Also Conn et al. [11]stated that TSH was 
significantly $(\mathrm{p}<0.03)$ depressed at both 4 and 8 weeks and Free T4 was significantly $(\mathrm{p}<0.01)$ raised above baseline at 8 weeks but not 4 weeks following contrast administration in the study conducted on73 patients.

Another Turkish study Özkan et al. [12] conducted on 101 patients showed that TSH levels decreased significantly at 4 weeks $(\mathrm{p}=0.003)$ and 8 weeks $(\mathrm{p}=0.008)$ and no statistically significant change was observed in fT4 and fT3 levels at weeks 4 and 8 compared to the baseline levels ( $\mathrm{p}>0.05$ ) after contrast media used for coronary angiography.

\section{IV.CONCLUSION}

Administration of Iodinated Contrast Media (ICM) associated with thyroid dysfunction mainly hypothyroidism (Subclinical or Overt) so we should closely monitor patients after receiving ICM especially who have thyroid dysfunction.

\section{REFERENCES}

[1]. Hall, J.E.,. Guyton and Hall textbook of medical physiology eBook 2015: Elsevier Health Sciences.

[2]. DuY., Y. Gao, F. Meng et al.,. Iodine deficiency and excess coexist in china and induce thyroid dysfunction and disease: a cross-sectional study. PLoS ONE 2014, 9(11), e111937 doi: 10.1371/journal.pone.0111937..

[3]. Leung A.M. and L.E. Braverman, Iodineinduced thyroid dysfunction. Current opinion in endocrinology, diabetes, and obesity2012., 19(5), 414.

doi: 10.1097/MED.0b013e3283565bb2.

[4]. Hsieh M.S., C.S. Chiu, W.C. Chen, et al., . Iodinated contrast medium exposure during computed tomography increase the risk of subsequent development of thyroid disorders in patients without known thyroid disease: a nationwide population-based, propensity score-matched, longitudinal followup study. Medicine (Baltimore). 2015 Dec;94(50):e2279. doi: 10.1097/MD.0000000000002279.

[5]. Andreucci M., R. Solomon, and A. Tasanarong,. Side effects of radiographic contrast media: pathogenesis, risk factors, and prevention. Biomed Res Int. 2014;2014:741018. doi: 10.1155/2014/741018.

[6]. Lee S.Y., C.M. Rhee, A.M. Leung,et al.,. A review: radiographic iodinated contrast mediainduced thyroid dysfunction. J Clin Endocrinol Metab. 2015 Feb;100(2):376-83. doi: 10.1210/jc.2014-3292.

[7]. Imai E., M. Horio, K. Nitta, et al.,. Estimation of glomerular filtration rate by the MDRD study equation modified for Japanese patients with chronic kidney disease. Clin Exp Nephrol. $2007 \quad$ Mar;11(1):41-50. DOI:10.1007/s10157-006-0453-4

[8]. Gartner, W. and M. Weissel ,. Do iodine containing contrast media induce clinically relevant changes in thyroid function parameters of euthyroid patients within the first week?. Thyroid. 2004 Jul;14(7):521-4. DOI:10.1089/1050725041517075.

[9]. Moradirizi M., M. Mirhoseini, A. Khaledifar, et al.,. Examining the effect of iodized contrast agent of coronary heart angiography in people without thyroid gland disorders. Bali Medical Journal 2016, 5(3), 104-110.Doi: 10.15562/bmj.v5i3.318.

[10]. Koroscil T.M., P.R. Pelletier, Slauson et al.,. Short-term effectsof coronary angiographic contrast agents on thyroid function. Endocrine Practice 1997, 3(4), 219-221. DOI:10.4158/EP.3.4.219.

[11]. Conn ,J.J., M.J. Sebastian., D. Deam, et al.,. A prospective study of the effect of nonionic 
contrast media on thyroid function. Thyroid 1996, $6(2)$, 107-110. DOI:10.1089/thy.1996.6.107.

[12]. Özkan S., A.S. Oysu, K. Kayatas, et al.,. Thyroid functions after contrast agent administration for coronary angiography: a prospective observational study in euthyroid patients. Anadulu Kardiyoloji Dergisi: AKD2013, 13(4), 363. DOI:10.5152/akd.2013.134.

\section{Cite this article as :}

Khaled S. El-Hadidy, Rania E. Sheir, M.N. Salem, Ahmed M. EL-Dien, Yasser A. Abd El-Hady, "Effect of Contrast Media used in Coronary Angiography on Thyroid Function", International Journal of Scientific Research in Science and Technology (IJSRST), Online ISSN : 2395-602X, Print ISSN : 2395-6011, Volume 6 Issue 4, pp. 339-344, JulyAugust 2019. Available at doi : https://doi.org/10.32628/IJSRST196468 Journal URL : http://ijsrst.com/IJSRST196468 